\section{Failure of ECS to produce retrograde amnesia following partial reinforcement training ${ }^{1}$}

\author{
A. GRANT YOUNG and E. $H$. \\ GALLUSCIO, Louisiana State University, \\ Baton Rouge, La. 70803
}

Twenty-eight naive male albino rats were trained to lever press for sucrose. Half of the $S$ s were trained on a continuous-reinforcement schedule (CRF), and the other half of the $S \mathrm{~s}$ were trained on a fixed-ratio (FR) schedule. On treatment day, for half of the $S s$ in each group, a lever press produced foot shock followed by ECS. For the remaining Ss, a lever press produced foot shock only. Results showed that ECS produced amnesia for the foot shock only in CRF-trained Ss.

The fact that electroconvulsive shock (ECS) seems to produce retrograde amnesia (RA) when administered shortly after a learning trial is well established (Spevack \& Suboski, 1969). Perhaps the most widely accepted hypothesis to account for this phenomenon suggests that memory consolidates over time. For example, Hebb (1949) has suggested that following sensory input, the consolidation of memory is effected through a process of reverberation of impulses in CNS circuits. This process results in a structural modification such that the ability of one neuron to excite another is changed in a relatively permanent manner. The massive electrical interference of ECS should disrupt memory consolidation if applied during the reverberatory phase but should have no effect if applied after the structural change in the neuron has been effected.

Although a number of studies (e.g., Heriot \& Coleman, 1962; Madsen \& McGaugh, 1961) have demonstrated that a single ECS does not appear to have aversive qualities, Hudspeth, McGaugh, \& Thompson (1964) have shown that repeated ECS is aversive and have suggested that only studies using one-trial learning and a single ECS bear on consolidation theory. A typical procedure is to administer aversive stimulation, such as foot shock, upon the emission of a previously learned response. The aversive stimulation results in a suppressed rate of responding; however, if ECS is administered shortly after the aversive stimulation, the result seems to be RA for this one-trial learning.

Recently, Adams, Peacock, \& Hamrick (1967) reported findings that do not support a consolidation interpretation of the effects of ECS. In that study, two groups of rats were trained to lever press, one group on a continuous-reinforcement schedule (CRF) and the other on a fixed-ratio schedule (FR 5). When Ss had reached a stable rate of responding, on pretest day a lever press was followed by foot shock. For half the Ss in each group, foot shock was followed by a single ECS; the other half received no ECS. All Ss were then subjected to a short retraining period. Results showed that, during retraining, the CRF group that received foot shock plus ECS had a significantly higher response rate than the CRF group that received foot shock only and, in fact, showed no suppression of response rate. Both FR 5 groups, however, showed significantly suppressed response rates not significantly different from each other, although one group had received foot shock plus ECS and the other group had received foot shock only.

These findings do not support consolidation theory; however, it seems possible to question these results because, during acquisition, $S$ s received training until they reached a "stable rate of responding." The total number of responses was uncontrolled prior to treatment, and this difference in experience among Ss might be reflected in response rate during testing. Additionally, after the administration of foot shock, $S$ was removed from the operant chamber, ear clips were attached, and ECS was then administered. This would necessarily result in some variability in the time interval between the offset of shock and the administration of ECS, and numerous studies have shown that this time interval is an important variable (Spevack \& Suboski, 1969).

The present study was therefore designed to determine the effect of ECS on response suppression following training under FR and CRF conditions, with the amount of training and foot-shock/ECS time interval constant.

\section{SUBJECTS}

The Ss were 28 naive male albino rats, $150-175 \mathrm{~g}$ in weight at the start of the experiment.

\section{APPARATUS}

The apparatus consisted of two identical Scientific Prototype operant chambers, each enclosed in a sound-insulated, ventilated box. Each operant chamber had a grid floor, and fitted on the end wall was a retractable lever and a liquid dipper than dispensed $.01 \mathrm{ml}$ of a $40 \%$ sucrose solution, used as reinforcement. All E-controlled events were operated by an electronic programming device.

\section{PROCEDURE}

Upon arrival at the laboratory, Ss were placed in individual cages and kept on an ad lib food and water schedule for 4 days, after which $S$ s were placed on a food-deprivation schedule of $10 \mathrm{~g}$ Purina chow every $24 \mathrm{~h}$. Water was available in the cages at all times, and Ss were fed approximately $10 \mathrm{~min}$ after each experimental session.

From the 5 th to the 9 th day, Ss were handled in pairs for 5 min daily, and on the 10th day, Ss began magazine training on a VI $30-\mathrm{sec}$ schedule. Experimental periods consisted of 20 presentations of the dipper and were continued for 4 days. On the 14th day, all Ss were conditioned to lever press and, on the following day, were allowed to make 100 reinforced responses. On the 16th day, Ss were divided randomly into two groups, FR and CR, and began acquisition training. For the FR group, acquisition was under a FR 5 reinforcement schedule, and for the $C R$ group, acquisition was under a CRF schedule. All Ss were given 100 lever presses daily for 10 days. On the 100th lever press each day, the lever retracted, ending the session. Throughout acquisition, each $S$ wore ear-clip electrodes for purposes of adaptation. On treatment day, fine wire attached to these electrodes exited through the top of the operant chamber to an ECS source.

On the day following completion of acquisition, each group was subdivided randomly, resulting in the following four groups:

\section{Groups CR (ECS) and FR (ECS)}

For Ss in these two groups, the first lever press on treatment day produced a 9-mA foot shock of 2-sec duration, delivered through the grid floor, and the lever retracted. The offset of foot shock initiated the onset of an ECS delivered through the ear-clip electrodes. ECS was $50 \mathrm{~mA}$ of $500-\mathrm{msec}$ duration.

\section{Groups CR (SO) and FR (SO)}

For $S s$ in these two groups, treatment was identical to the two groups above except that foot shock was not followed by ECS.

On the day following treatment, Ss were subjected to a 10 -min extinction session. During extinction, the stimulus conditions were the same as during acquisition except that the dipper was inoperative. 
Table 1

Mean Number of Lever Presses in Extinction

\begin{tabular}{lcc} 
Group & $\begin{array}{c}\text { Mean } \\
\text { Responses } \\
\text { First } \\
\text { Minute }\end{array}$ & $\begin{array}{c}\text { Total } \\
\text { Mean } \\
\text { Responses }\end{array}$ \\
\hline CR (ECS) & 27.29 & 157.3 \\
FR (SO) & 6.50 & 110.8 \\
FR (ECS) & 6.16 & 86.3 \\
CR (SO) & 5.22 & 70.7 \\
\hline
\end{tabular}

\section{RESULTS}

The total number of responses made by each $S$ in extinction were recorded, and results showed that more responses were made by Group CR (ECS), followed in order by Groups FR (SO), FR (ECS), and $\mathrm{CR}$ (SO). These data were subjected to an analysis of variance that showed that neither main effect of schedule nor treatment was significant at the .05 level; however, the Schedule by Treatment interaction was significant beyond the .01 level. The data were therefore subjected to analyses of variance for simple effects that showed the comparison CR (ECS) vs FR (ECS) significant beyond the .05 level and the comparison CR (ECS) vs CR (SO) significant beyond the .01 level. All other group comparisons showed $\mathrm{p}>05$. The total number of responses made by each $\mathbf{S}$ during the first $60 \mathrm{sec}$ of extinction were separately recorded, subjected to the same statistical analysis as above, and the same results were obtained except that the significance levels exceeded .001. The mean number of responses in extinction for each group is shown in Table 1 .

Table 2 shows the mean number of responses per minute for all groups on the last 2 days of acquisition and on test day. Acquisition response rates were significantly higher for FR Ss than for CRF Ss $(p<.001$, Mann-Whitney U test $)$. All Ss that did not receive ECS showed a significant suppression of response rate, which indicates that one-trial learning occurred in both $\mathrm{CR}$ and FR groups $(p<.05$, Friedman analysis of variance of ranks). Response rates on test day for Groups FR (SO) and FR (ECS) were not significantly different (Mann-Whitney $U$ test), which indicates that ECS did not eliminate suppression of response rate for Group FR (ECS). Only the CR (ECS) group showed no significant suppression of response rate.

\section{DISCUSSION}

The finding that the CR (ECS) group made significantly more responses in extinction that did the CR (SO) group is typical; however, the most critical finding in this study is that the immediate administration of ECS following foot shock did not eliminate suppression of responding in the FR (ECS) group.

These results are in agreement with those of Adams et al (1967) and do not support a consolidation-of-memory hypothesis. If the effect of ECS is a disruption of memory-consolidation processes, then this disruption should occur regardless of the schedule of reinforcement during acquisition. Adams et al suggested that, rather than producing RA for aversive stimulation, ECS produces disinhibition in that it removes the inhibition of responding. Since

Table 2

Mean Number of Responses Per Minute

\begin{tabular}{lcr}
\hline Group & Acquisition & Test \\
\hline FR (SO) & 37.7 & 11.1 \\
FR (ECS) & 37.8 & 8.6 \\
CR (ECS) & 21.9 & 15.7 \\
CR (SO) & 24.7 & 7.1 \\
\hline
\end{tabular}

disinhibition does not occur if the response rate is high, the effect of ECS following aversive stimulation should be different for Ss trained on a FR schedule, which produces high response rates, and for Ss trained on a CRF schedule, which produces low response rates. Although such an idea would seem to be supported by the present results, it is probably untenable due to the time interval between the administration of ECS and the testing for suppression.

The present results are difficult to interpret because it is not clear whether ECS failed to eliminate suppression of responding in the FR (ECS) group due to the effect of the partial-reinforcement schedule itself or due to the higher response rate which a partial-reinforcement schedule generates.

\section{REFERENCES}

ADAMS, H. E., PEACOCK, L. J., \& HAMRICK, D. D. ECS and one-trial learning: Retrograde amnesia or disinhibition? Physiology \& Behavior, 1967, 2, 435-437

HEBB, D. O. The organization of behavior. New York: Wiley, 1949.

HERIOT, J. T., \& COLEMAN, P. D. The effect of electroconvulsive shock on retention of a modified "one-trial" conditioned avoidance. Journal of Comparative \& Physiological Psychology, 1962, 55, 1082-1084.

HUDSPETH, W. J., MOGAUGH, J. L., \& THOMPSON, C. W. Aversive and amnesic effects of electroconvulsive shock. Journal of Comparative \& Physiological Psychology, 1964, 57, 61-64.

MADSEN, M. C., \& McGAUGH, J. L. The effect of ECS on one-trial avoidance learning. Joumal of Comparative \& Physiological Psychology, $1961,54,522-523$.

SPEVACK, A. A., \& SUBOSKI, M. D. Retrograde effects of electroconvulsive shock on learned responses. Psychological Bulletin, 1969, 72, 66-76.

$$
\text { NOTE }
$$

1. This research was supported in part by a grant from the Graduate Research Council, LSU, to the first author. 